\title{
LA REPARACIÓN DE LOS DAÑOS DERIVADOS DEL PRÉSTAMO DE VEHÍCULOS. PERSPECTIVAS DE UNA REFORMA
}

\author{
JAVIER BARCELÓ DOMÉNECH
}

\section{INTRODUCCIÓN}

A la responsabilidad civil dedica el Código civil los arts. 1.902 a 1.910 , que son objeto de una constante aplicación por la jurisprudencia, hasta el punto de hacer de la responsabilidad civil uno de los sectores más vivos del ordenamiento jurídico. El sistema del Código civil está basado, fundamentalmente, en la culpa del sujeto llamado a responder del daño causado. Sin embargo, la interpretación de las normas del Código civil ha experimentado una importante evolución como consecuencia del nuevo enfoque de la responsabilidad civil, que atiende, sobre todo, a la necesidad de proteger la persona y sus bienes jurídicos ${ }^{1}$. El legislador no ha sido tampoco ajeno a este cambio de mentalidad, como se demuestra por la continua introducción de regímenes especiales de responsabilidad, en los que se ignora la culpa con la finalidad de facilitar la indemnización del daño causado².

La responsabilidad civil es también objeto de tratamiento por el Código penal, siendo posible afirmar la existencia de una doble regulación en nuestro ordenamiento jurídico. Actualmente, la regulación de la materia en este Código se encuentra dividida: por un lado, en el Capítulo II, Título II, Libro I, encontramos los preceptos referidos a los sujetos responsables de los delitos o faltas (arts. 19 a 22); por otro, tenemos el Título IV del Libro I dedicado al contenido de la responsabilidad civil (arts. 101 a 111); y, finalmente, la extinción de la responsabilidad es prevista por el art. 117, dentro del Título V del Libro I, donde se efectúa

1 Sobre esta evolución, vid. L. DÍEZ-PICAZO, Estudios sobre la jurisprudencia civil, vol. $1^{\circ}$, Madrid, 1979, p. 276; J.J. LÓPEZ-JACOISTE, «Cien años de horizonte extracontractual», en Centenario del Código civil (1889-1989), t. II, Madrid, 1990, p. 1.149.

2 Sobre los sectores afectados por esta tendencia, vid. G. ALPA, «Le frontiere attuali della responrabilità», La Nuova Giurisprudenza Civile Commentata, 1994, II, p. 85. En nuestra doctrina, señala F. PANTALEON PRIETO, en Comentario del Código civil (art. 1.902), dir. C. PAZ-ARES / L. DÍEZ-PICAZO / R. BERCOVITZ / P. SALVADOR CODERCH, t. II, Madrid, 1991, pp. 1.995 y 1.996, como responsabilidades civiles independientes de la culpa establecidas por la ley: a) accidentes de circulación; b) navegación aérea; c) accidentes nucleares; d) accidentes de caza; e) daños derivados del consumo de bienes o la utilización de productos o servicios; f) responsabilidad patrimonial de las Administraciones públicas, y la de sus concesionarios y contratistas, por los daños derivados del «funcionamiento normal o anormal de los servicios públicos»; y g) responsabilidad del Estado por los daños causados por error judicial o funcionamiento anormal de la Administración de Justicia. 
una remisión a las reglas del Derecho civil. Esta técnica legislativa, cuya razón histórica se remonta al hecho de que la codificación penal fuese anterior a la civil $^{3}$, ha sido objeto de crítica en la doctrina ${ }^{4}$, que llega a proponer una unificación de ambas regulaciones 5 . Sin embargo, el Proyecto de Código penal de 26 de septiembre de 1994 opta por seguir regulando, incluso con mayor amplitud, la responsabilidad civil derivada del delito o falta (arts. 109 a 126).

La adaptación de las normas de los Códigos civil y penal a las nuevas circunstancias ha sido llevada a cabo por la jurisprudencia ${ }^{6}$. Desde esta perspectiva, los problemas de responsabilidad civil surgidos en torno a la cesión gratuita de automóviles constituyen uno de los ejemplos más claros, en nuestro ordenamiento, de la inadecuación de los textos legales vigentes y del esfuerzo de la jurisprudencia por encontrar una solución que dé cumplida respuesta a las necesidades de protección de la víctima del daño.

Los problemas de responsabilidad civil que presenta el préstamo de vehículos son de muy diversa índole. Sin embargo, nuestro interés se centra en la responsa-

3 Así lo advierte S. DÍAZ ALABART, «La responsabilidad por los actos ilícitos dañosos de los sometidos a patria potestad o tutela», $A D C, 1987$, p. 799 .

4 Se considera que las normas sobre responsabilidad civil del Código penal son normas civiles, que atienden a una finalidad compensatoria (no represiva, por tanto). En este sentido, vid. F. GALIANA URIARTE, «Problemas de la responsabilidad civil delictual. El tercero perjudicado», $A D P, 1966$, pp. 200 y 201; J.M. RODRÍGUEZ DEVESA, «Responsabilidad civil derivada de delito o falta y culpa extracontractual», en Libro Homenaje a Jaime Guasp, Granada, 1984, p. 519; S. DÍAZ ALABART, «La facultad de moderación del artículo 1.103 del Código civil», $A D C, 1988$, p. 1.165, nota 51; E. FONT SERRA, La acción civil en el proceso penal. Su tratamiento procesal, Madrid, 1991, pp. 15 y 16; F. PANTALEON PRIETO, en Comentario del Código civil (art. 1.902)... cit., p. 1.994 , p. 461.

En esta dirección se manifiesta también la STS (Sala $2^{a}$ ) 21 de noviembre de 1991 (RAJ n $^{\circ}$ 8.442): «... estamos en presencia de normas civiles que no pierden su naturaleza por estar disciplinadas en el Código Penal y ejercitarse las correspondientes acciones en el proceso penal».

A diferencia del Proyecto de Código penal de 1994, el Anteproyecto de 1990, partiendo de unos parámetros contrarios, remitía en bloque la materia al Código civil. Sobre el particular, vid. R. GARCÍA LARAÑA, «La responsabilidad civil ex delicto en el Anteproyecto de Código penal de 1992», La Ley, 1992-3, p. 1.048.

5 El sometimiento a unos mismos principios evitaría los muchos y graves problemas que hoy plantea su regulación separada, siendo la consecuencia lógica de admitir la distinta naturaleza de la pena y de la responsabilidad civil. Lo cual no impediría que el Juez penal, por razones de economía procesal, entendiese, en el mismo procedimiento, de la indemnización de los perjuicios ocasionados por el delito o falta. Sobre ello, vid. F. PANTALEON PRIETO, «Comentario a la STS (Sala I ${ }^{a}$ ) 25 de junio de 1983», CCJC, n 3, p. 794; J.M. RODRÍGUEZ DEVESA, op.cit., pp. 526 y ss.; A. CABANILLAS SÁNCHEZ, en Comentario al Código Civil y a las Compilaciones Forales (arts. 1.092 y 1.093 C.c.), dir. M. ALBALADEJO, t. XV, vol. $1^{\circ}$, Madrid, 1989, p. 222.

6 Al respecto, vid. C. ROGEL VIDE, La responsabilidad civil extracontractual en el Derecho español, Madrid, 1977, p. 50; A. CABANILLAS SÁNCHEZ, «La responsabilidad civil por daños a personas o a cosas a consecuencia de la alteración del medio ambiente y su aseguramiento», RES, $1988, \mathrm{n}^{\circ} 55, \mathrm{pp} .33$ y ss. 
bilidad que cabe exigir al propietario ${ }^{7}$ del automóvil por el daño que causa la persona a la que cedió su uso. Se comprenderá esta elección, si se tiene en cuenta la orientación actual del Derecho de daños hacia la búsqueda del patrimonio que mayores garantías ofrezca para la indemnización de los perjudicados y que, en el caso que nos ocupa, viene casi siempre constituido por el del propietario del vehículo (y su entidad aseguradora).

Estas situaciones de cesión gratuita de automóvil encajan en el marco jurídico del comodato. El Código civil, bajo la denominación de préstamo, regula dos contratos distintos: el comodato y el préstamo simple o mutuo; su definición se encuentra en el párrafo primero del art. 1.740: «Por el contrato de préstamo, una de las partes entrega a la otra, o alguna cosa no fungible para que use de ella por cierto tiempo y se la devuelva, en cuyo caso se llama comodato, o dinero u otra cosa fungible, con condición de devolver otro tanto de la misma especie y calidad, en cuyo caso conserva simplemente el nombre de préstamo». A los efectos de este trabajo, interesa destacar una de las notas características del comodato, que es la gratuidad, pues «si interviene algún emolumento que haya de pagar el que adquiere el uso, la convención deja de ser comodato» (art. 1.741 C.c.).

Normalmente, la cesión del vehículo está motivada por los vínculos familiares o de amistad que unen al comodante y comodatario. Son cesiones muy frecuentes, sobre todo, en el entorno familiar, llegando la jurisprudencia a presumir aquí el consentimiento para la utilización del vehículo ${ }^{8}$.

La jurisprudencia penal ha basado la condena del propietario del vehículo, como responsable civil subsidiario, en el art. 22.I C.p., norma ésta que declara la responsabilidad de «las personas, entidades, organismos y empresas dedicadas a cualquier género de industria, por los delitos o faltas en que hubiesen incurrido sus empleados o dependientes en el desempeño de sus obligaciones o servicio».

La jurisprudencia civil, menos abundante que la penal en esta materia, no siempre ha basado en la misma norma la declaración de responsabilidad civil del comodante. Como veremos, los razonamientos seguidos por las sentencias de la Sala $1^{\text {a }}$ del TS no clarifican, a veces, este importante dato. En todo caso, estas sentencias plantean la posible aplicación del art. 1.903.IV C.c., conforme al cual

7 Como veremos, no siempre puede ser acertado hablar de propietario del vehículo, puesto que quien presta el vehículo puede disponer de él en virtud de un título distinto y, sin embargo, ser procedente que se declare su responsabilidad. Así, en la STS (Sala 2a) 30 de mayo de $1992\left(\right.$ RAJ n $^{\circ}$ 4.963), la propietaria del vehículo se encontraba ausente durante largo tiempo en América, siendó su marido el poseedor del vehículo y el que entregó las llaves del mismo al conductor.

8 Así, afirma la STS (Sala 2a 15 de junio de 1989 (RAJ $\left.{ }^{\circ} 5.123\right)$ : «... en los supuestos en que el hijo conduce el vehículo propiedad de los padres o de alguno de ellos, éstos o el progenitor concreto que proceda, responde civil y subsidiariamente por aquél porque hay que presumir (presunción aceptable porque no afecta a ningún tipo de culpabilidad) que lo hace con su consentimiento expreso, tácito o presunto y bajo su dependencia y desde luego en su beneficio, interpretada esta palabra en su sentido más amplio posible en cuanto redunda en su satisfacción material o moral de los padres». 
son responsables los empresarios de los perjuicios causados por sus dependientes en el ejercicio de sus funciones.

Antes de examinar la jurisprudencia, es necesario saber si los arts. 22.I C.p. y 1.903.IV C.c. ofrecen una solución adecuada para imponer responsabilidad en el comodante. Lo cual obliga a constatar si los presupuestos de aplicación de ambos preceptos permiten o no su aplicación a la cesión gratuita de vehículos.

Entre los presupuestos o condiciones de aplicación de los arts. 22.I C.p. y 1.903.IV C.c., figura la relación de dependencia. ¿Existe dependencia entre el conductor y el propietario del vehículo? La respuesta debe ser negativa. No existe dependencia, ni siquiera interpretando esta noción con la máxima amplitud. La autorización de uso del vehículo no es equiparable al control, dirección, sometimiento a la organización, etc. que integra el concepto de dependencia.

La forma en que se ha despejado la interrogante planteada permite establecer, en una primera aproximación, dos importantes consecuencias. Por un lado, como vimos, que la jurisprudencia busca una persona solvente que pueda indemnizar el daño causado, determinando la propia naturaleza de estas situaciones (piénsese, por ejemplo, en los frecuentes préstamos de vehículos de padres a hijos) que el propietario sea el que mayor solvencia ofrezca. Por otro, que la aplicación de los arts. 22 C.p. y 1.903 C.c. revela una clara deficiencia de nuestro ordenamiento jurídico, al no contar con una norma que expresamente prevea este supuesto, declarando la responsabilidad civil del propietario o detentador ${ }^{9}$ del vehículo por los daños que causa la persona que fue autorizada a conducirlo, desembocando, por tanto, en una auténtica hipertrofia aplicativa de estos preceptos.

Esta deficiencia normativa fue puesta de manifiesto por la propia jurisprudencia. La STS (Sala $2^{\mathrm{a}}$ ) 14 de enero de $1963^{10}$, al decidir sobre un caso de alquiler de vehículo sin conductor (supuesto tampoco previsto expresamente por la ley y que plantea la misma problemática que la cesión gratuita de vehículo), advierte de los peligros de una interpretación que haga prácticamente irreconocible el art. 22 C.p. y señala que «el interés público de proteger económicamente al perjudicado por el delito, ante la frecuencia cada vez mayor de la figura contractual del alquiler de coches sin chófer, podrá ser satisfecha por el legislador con la modificación del citado precepto del C.P. o por el medio que técnicamente se considere más adecuado, pero no por los Tribunales, mediante una interpretación arbitraria y desorbitada de la Ley». A pesar de la claridad del pronunciamiento, la dirección jurisprudencial dominante se inclina por aplicar el art. 22 C.P. al arrendador, aun cuando se construya, a tales fines, una fictica relación de dependencia.

9 F. REGLERO CAMPOS, Accidentes de circulación: responsabilidad civil y seguro, Madrid, 1990, p. 124, nota 139, utiliza el término «detentador» para referirse a la persona que, sin ser propietaria del vehículo, dispone de éste en virtud de un título que le legitima para su uso, disfrute o explotación. A pesar de las críticas que pueda suscitar el empleo de este término, lo considera preferible al de «poseedor», presente en algunas resoluciones judiciales.

$10 \quad \mathrm{RAJ} \mathrm{n}^{\circ} 82$. 
En lo que concierne al Código civil, sabido es que no contiene una norma que, con carácter general, establezca la responsabilidad por el hecho de las cosas y la jurisprudencia no ha desarrollado una responsabilidad de este tipo a partir de algunos datos normativos valiosos como el art. 1.908 C.c., que hubiese permitido hacer responsable al propietario del vehículo (o a la persona que puede disponer de él) por el control que ejerce sobre el mismo, sin que pueda modificar esta situación el uso que un tercero haga del vehículo (el préstamo a un amigo o familiar no supone necesariamente que desaparezca el control sobre el instrumento susceptible de crear riesgos) ${ }^{11}$.

El Código penal no prevé tampoco la responsabilidad civil subsidiaria del propietario del vehículo por los delitos o faltas cometidos por la persona a la que se cedió su uso. Existe, además, un problema añadido, que complica extraordinariamente las cosas: ninguna norma del Código penal determina la responsabilidad civil de los padres por los delitos o faltas cometidos por sus hijos mayores de 16 y menores de 18 años, a diferencia del art. 1.903.II C.c. que sí recoge este supuesto. Esta omisión hace todavía más necesario el recurso al art. 22 C.p. para encontrar una persona solvente, que son los padres $^{12}$.

11 En Francia, la responsabilidad por el hecho de las cosas ha supuesto uno de los ejemplos más importantes de elaboración jurisprudencial del Derecho, estando esta responsabilidad vinculada a los accidentes automovilísticos hasta la entrada en vigor de la legislación especial: vid., sobre ello, F. CHABAS, Le droit des accidents de la circulation après la reforme du 5 juillet 1985, Paris, 1985, p. 13.

Durante mucho tiempo, el párrafo primero del art. 1.384 del Code había sido considerado un texto sin valor propio, que se limitaba a anunciar los preceptos que le seguían, de forma tal que únicamente se respondía de los daños ocasionados por las cosas a las que aludía el Código civil: animales (art. 1.385) y edificios (art. 1.386). Hasta finales del siglo XIX, nada hace pensar en una responsabilidad de carácter general; fuera de los casos expresamente previstos por el legislador, se considera que una cosa no era sino el instrumento de una acción humana y debía apreciarse, en base al art. 1.382 C.c., si el autor de la acción era o no culpable. Señala A. BENABENT, Droit civil, Les obligations, Paris, 1987, p. 214 que, con el desarrollo del maquinismo y la multiplicación de los accidentes en los cuales la intervención del hombre resulta difícil de determinar y, por tanto, la culpa imposible de probar, la necesidad de proteger a las víctimas de esos accidentes conduce a la jurisprudencia a establecer un principio general de responsabilidad por el hecho de las cosas, que tendrá su base legal en el párrafo primero del art. 1.384 C.c. Esta responsabilidad tiene naturaleza objetiva, no viniendo el sujeto responsable determinado por la simple tenencia material de la cosa, sino por el elemento decisivo de la autoridad que ejerce sobre la cosa, por el poder independiente de control y dirección.

La jurisprudencia española no ha seguido el camino de esta evolución, aun cuando la doctrina ha destacado la posibilidad de construir una responsabilidad de este tipo, con base en los arts. 1.905 y ss. C.c. En este sentido, C. ROGEL VIDE, op. cit., pp. 183 y ss., destaca las posibilidades que ofrecen los arts. 1.908 y 1.909 , desconocidos por el Código de Napoleón, para emprender un camino semejante al recorrido por la jurisprudencia francesa. Por su parte, R. DE ÁNGEL YAGÜEZ, Tratado de responsabilidad civil, Madrid, 1993, pp. 560 y ss., prefiere hablar de «responsabilidad por actividades peligrosas», a la manera del art. 2.050 C.c. italiano, cuando analiza la posibilidad expansiva de los arts. 1.905 y ss. C.c.

12 Sobre ello, vid. L. ALONSO PRIETO, «Derecho sustantivo privado: por qué «no están» los padres en el artículo 22 del Código penal», en Estudios de Derecho judicial de la circulación. Hacia un régimen unitario de la responsabilidad civil, Gijón, 1972, p. 23; C. LÓPEZ BELTRÁN DE HEREDIA, La responsabilidad civil de los padres por los hechos de sus hijos, Madrid, 1988, pp. 42 
Finalmente, no ofrece solución al problema planteado la regulación de la responsabilidad civil automovilística, ya que el art. 1 del Texto Refundido de la Ley de Uso y Circulación de Vehículos de Motor, de 24 de diciembre de 1962, en su última redacción por el RDL 1301/1986, de 28 de junio, centra la obligación de indemnizar en el conductor, sin decir nada acerca de la responsabilidad de otras personas que ejercen un control sobre el automóvil, como sería el caso del propietario $^{13}$.

\section{ANÁLISIS JURISPRUDENCIAL}

\section{Jurisprudencia penal}

La solución dada al préstamo amistoso de vehículo ha ido variando en el tiempo, por lo que es posible efectuar una clasificación de la jurisprudencia en diferentes etapas.

\section{A) Primera etapa: inaplicación del art. 22 C.p.}

En esta primera fase, entran aquellas sentencias que niegan la aplicación del art. 22 C.p. y, por tanto, no se declara la responsabilidad civil subsidiaria del comodante $^{14}$. La STS (Sala $2^{\mathrm{a}}$ ) 24 de septiembre de $1966^{15}$ expresa adecuadamente este criterio jurisprudencial, al señalar que «la simple y abstracta autorización del uso de un automóvil, no genera de por sí vínculo de dependencia o servicio, por lo que no da lugar a la responsabilidad civil subsidiaria sino cuando a aquélla se yuxtaponen otros factores concretos que permiten configurar en cada caso una situación de subordinación del autorizado al autorizante».

y 43; E. GÓMEZ CALLE, «Comentario a la STS (Sala 1ª) 27 de septiembre de 1990», CCJC, $\mathrm{n}^{\circ} 24$, p. 1.027 .

Consciente de tales problemas, el art. $120.1^{\circ}$ del Proyecto de Código penal de 1994 establece la responsabilidad civil subsidiaria de «los padres o tutores, por los daños y perjuicios causados por los delitos o faltas cometidos por los sujetos a su patria potestad o tutela y que vivan en su compañía, siempre que hubiere por su parte culpa o negligencia».

13 Vid. G. GUIJARRO CONTRERAS, «Responsabilidad civil automovilística», $A D C, 1963$, pp. 641 y ss.; F. REGLERO CAMPOS, Accidentes de circulación..., cit., pp. 127 y 128; M.J. MORILLAS JARILLO, El seguro de automóvil: el aseguramiento obligatorio de la responsabilidad civil automovilística, Barcelona, 1992, p. 405.

14 SSTS (Sala 2a) 1 de junio de 1935 (RAJ n 1.135), 1 de abril de 1960 (RAJ no 1.157), 3 de junio de 1961 ( ( $\mathrm{JJ} \mathrm{n}^{\circ}$ 2.153), 19 de noviembre de 1962 (RAJ n ${ }^{\circ} 4.238$ ), 5 de diciembre de 1962 (RAJ $\mathrm{n}^{\circ} 4.574$ ), 28 de septiembre de 1964 (RAJ n ${ }^{\circ} 4.009$ ), 14 de octubre de 1965 (RAJ n ${ }^{\circ} 4.647$ ), 24 de septiembre de 1966 (RAJ n 3.845 ), 28 de abril de 1971 (RAJ n n $^{\circ} .831$ ), 30 de noviembre de 1981 $\left(\mathrm{RAJ} \mathrm{n}^{\circ} 4.460\right)$ y 16 de diciembre de $1986\left(\mathrm{RAJ}^{\circ}{ }^{\circ}\right.$ 7.932). Las dos últimas sentencias, por la fecha en que fueron dictadas, bien pueden ser consideradas excepcionales.

$15 \quad \operatorname{RAJ}^{\circ} 3.845$. 
La negativa a declarar la responsabilidad del propietario del vehículo se justifica en la falta de dependencia. Sólo se impondía esta responsabilidad si se demuestra que, junto a la autorización para usar el vehículo, existía el cumplimiento de un encargo por cuenta del propietario, que permitiese hablar de un sometimiento a sus órdenes o instrucciones; de ahí que otro bloque de sentencias, tras constatar la existencia de dependencia, declaren la responsabilidad del propietario $e x$ art. 22 C.p. ${ }^{16}$.

\section{B) Segunda etapa: aplicación del art. 22 C.p.}

La Sala $2^{\mathrm{a}}$ del TS no siempre ha seguido el planteamiento que se ha expuesto, de forma que puede afirmarse que la dirección actualmente dominante se orienta en favor de la declaración de responsabilidad civil subsidiaria del propietario del vehículo, sin reparar si, en el caso debatido, existía o no dependencia.

Esta nueva etapa se abre con decisiones que formalmente sostenían la existencia de una relación de dependencia que, sin embargo, desmentía la realidad de los hechos ${ }^{17}$.

La jurisprudencia más reciente ha establecido una distinción entre la «cesión ocasional o para una finalidad concreta» y la «cesión genérica o sin límite de tiempo ni especificación de finalidad», afirmándose la responsabilidad del propietario en el primer caso y negándose en el segundo ${ }^{18}$. Esta interpretación plantea algunos interrogantes. Por una parte, es discutible que pueda equipararse el tiempo y el objeto de la cesión. Por otra, si de lo que se trata es de aplicar el art. 22 C.p., lo que debe analizarse es si concurren los presupuestos de aplicación de la norma, entre los cuales figura la dependencia; con otras palabras, si a la cesión de uso (cualquiera que sea su duración o su finalidad) se añade o no un sometimiento a las instrucciones del propietario, la prestación de un servicio bajo su dirección, etc., que permita constatar la existencia del vínculo de dependencia que exige el art. 22 C.p. Con ello queremos significar que la distinción puede ser muy impor-

16 SSTS (Sala $2^{\text {a }}$ ) 6 de noviembre de 1935 (RAJ n 2.085), 22 de enero de 1941 (RAJ n ${ }^{\circ} 101$ ), 17 de abril de 1961 (RAJ n ${ }^{\circ} 1.337$ ), 2 de enero de 1963 (RAJ n 23), 13 de abril de 1964 (RAJ n ${ }^{\circ}$ 1.914), 14 de mayo de 1964 (RAJ n ${ }^{\circ}$ 2.560), 15 de febrero de 1966 (RAJ n ${ }^{\circ} 875$ ), 6 de marzo de 1966 (RAJ n 1.304), 23 de junio de 1969 (RAJ n ${ }^{\circ} 3.753$ ), 16 de abril de 1970 (RAJ no 1.836), 20 de marzo de 1973 (RAJ n 1.366 ), 17 de abril de 1973 (RAJ n 1.766), 13 de febrero de 1978 (RAJ n ${ }^{\circ} 425$ ), 2 de marzo de 1979 ( $\mathrm{RAJ}^{\circ}{ }^{\circ} 2.083$ ) y 8 de marzo de 1990 (RAJ n ${ }^{\circ} 2.430$ ). Puede causar sorpresa la inclusión en esta primera fase de las decisiones más recientes, pero debe considerarse que se trataba de supuestos en los que se apreciaba, sin mayores dificultades, la existencia de dependencia.

17 SSTS (Sala $2^{\mathrm{a}}$ ) 6 de diciembre de $1973\left(\mathrm{RAJ} \mathrm{n}^{\circ} 4.915\right.$ ), 24 de febrero de 1978 (RAJ ${ }^{\circ} 496$ ), 1 de julio de $1978\left(\right.$ RAJ n $^{\circ} 2.769$ ), 28 de octubre de $1982\left(\right.$ RAJ n $\left.^{\circ} 5.704\right)$ y 20 de diciembre de 1991 (RAJ n' 9.577$)$.

18 SSTS (Sala $2^{\mathrm{a}}$ ) 16 de mayo de 1988 (RAJ n 3.663 ), 9 de febrero de 1989 (RAJ n 1.527 ), 22 de mayo de 1989 (RAJ n 4.238), 5 de diciembre de 1989 (RAJ n 9.439) y 10 de julio de 1990 (RAJ n ${ }^{\circ} 6.628$ ). 
tante si la norma que decidiese estos casos hiciera responsable a quien ejerce el control sobre el instrumento peligroso (y que, previsiblemente, se pierde en las cesiones de larga duración), pero no cuando todo gira en torno a la dependencia.

Además de los inconvenientes apuntados, encontramos algunas sentencias que hacen dudar de la propia consistencia de la distinción entre cesión permanente y cesión transitoria. Así, la STS (Sala 2a) 10 de octubre de $1991^{19}$ declara su adscripción a la más reciente doctrina acerca de la cesión permanente (que es la que se daba en el caso), a pesar de lo cual hace responsable al cedente por conocer que el usuario no tenía permiso de conducir. También parece desconocer esta doctrina la STS (Sala $2^{\mathrm{a}}$ ) 30 de mayo de $1992^{20}$, al declarar la responsabilidad civil subsidiaria en una cesión permanente que, curiosamente, se impone al poseedor y no al propietario.

A modo de conclusión, puede decirse que, con independencia del valor que quepa atribuir a esta distinción y del seguimiento de la misma por sentencias posteriores, el propietario del vehículo viene, en muchos casos, a responder por la vía del art. 22.I C.p. sin que exista el vínculo de dependencia que el propio precepto exige. Probablemente, encontremos en la STS (Sala $2^{\text {a }}$ ) 1 de diciembre de $1989^{21}$ el resumen más acertado de la posición dominante de la jurisprudencia: «Si bien es cierto, que entre el recurrente, propietario del vehículo, y el que lo utilizó y produjo con su conducta el hecho objeto de enjuiciamiento, sólo existía un vínculo de amistad, que nada tiene que ver con esa relación laboral de que nos habla el precepto, así como tampoco con otra conexión estrictamente jurídicolegal, no cabe olvidar que el hecho de la cesión del automóvil a un tercero, de manera voluntaria, supone aceptar el riesgo de lo que pueda ocurrir con la utilización de ese artefacto de por sí peligroso, no siendo aceptable que pueda quedar excluido de los resultados de ese riesgo aquella persona que inicialmente lo ha provocado o ha colaborado en él, de manera muy directa».

\section{Jurisprudencia civil}

En la Sala $1^{a}$ del TS, la posible responsabilidad de quien cede gratuitamente a otro el uso del vehículo se ha planteado en algunas sentencias, cuya interpretación no siempre es fácil. Como se dijo antes, se echa en falta una mayor claridad en los argumentos utilizados para la solución de estos casos.

$19 \operatorname{RAJ~}^{\circ} 7.061$.

$20 \operatorname{RAJ~n}^{\circ} 4.963$.

21 RAJ $n^{\circ} 9.372$. 
La primera referencia que encontramos, en esta materia, corresponde a la STS (Sala $\left.1^{\text {a }}\right) 23$ de febrero de $1976^{22}$. Los hechos eran los siguientes: la dueña de un automóvil lo prestó a su novio para un breve viaje, en el transcurso del cual se produjo un accidente. El conductor falleció, resultando don diversas lesiones otras dos personas que ocupaban el vehículo. La demanda fue estimada en todas las instancias.

Al plantear el recurso de casación, la propietaria del vehículo basó su defensa en la falta de dependencia que, a su juicio, determinaba una aplicación indebida del art. 1.903.IV C.c. Según afirmaba la recurrente, el simple consentimiento tácito para usar el coche no podía originar una relación de la misma entidad que la familiar o la laboral.

Los argumentos del TS para confirmar la sentencia de la Audiencia se contienen en los Considerandos sexto y séptimo, cuyo estudio por separado permite poner de manifiesto algunas contradicciones.

En primer término, afirma el Considerando sexto que «se pueden entender incluidos en el art. 1903 otros supuestos en los que exista o se genere alguna relación jurídica distinta de las que el precepto contempla ad exemplum, como pueden ser las de comodato, originado por la cesión gratuita y temporal que, el propietario de un automóvil asegurado hace a otra persona a la que ligan lazos familiares o cuasi familiares o de gran afecto, cuya relación crea deberes recíprocos».

El TS acude, por tanto, al carácter abierto del art. 1.903 C.c. para incluir en él una relación de comodato. Nos parece un argumento desacertado. Aun cuando se admitiese el carácter abierto de la norma ${ }^{23}$, no hay que olvidar que la clave del

22 RAJ n 880.

23 La doctrina mayoritaria se muestra partidaria del carácter limitativo del art. 1.903 C.c. Vid., por todos, M. ALBALADEJO, Derecho civil II. Derecho de obligaciones, vol. $2^{\circ}$, Barcelona, 1994, p. 484.

En Francia, tradicionalmente se había entendido que los supuestos previstos en el art. 1.384 del Code (equivalente a nuestro art. 1.903) tenían carácter excepcional, siendo la enumeración cerrada. Recientemente, sin embargo, la jurisprudencia ha establecido un criterio distinto en la sentencia de la Asamblea Plenaria de 29 de marzo de 1991 (arrêt Blieck). Un enfermo mental, internado en un centro de ayuda, provocó, mientras realizaba determinados trabajos que le fueron asignados para ser cumplidos en libertad, un incendio en el bosque de los demandantes. La demanda se dirige contra el centro y su asegurador, siendo estimada por el Tribunal civil en primera instancia, sobre la base de una presunta falta de vigilancia. El Tribunal de Apelación mantiene la condena, pero da una justificación distinta: la falta de vigilancia no tiene sentido al aplicarse un método moderno de tratamiento en libertad, por lo que más bien se trata del riesgo social creado por los métodos liberales de reeducación, que permite aplicar «la disposición del art. 1.384, párrafo $1^{\circ}$, del C.c., que enuncia el principio de presunción de responsabilidad por el daño causado por las personas de las que se debe responder». En el recurso de casación contra esta sentencia, se plantea que el Tribunal de Apelación había violado el párrafo primero del art. 1.384 C.c., dado que no hay otra responsabilidad por hecho ajeno distinta de 
sistema de responsabilidad por hecho ajeno del art. 1.903 C.c. se encuentra en el sometimiento de una persona a la vigilancia, dirección o control de otra, ya se trate de una relación paterno-filial, laboral o docente ${ }^{24} \mathrm{y}$, desde esta óptica, la falta de dependencia que se da en el caso impediría toda aplicación del art. 1.903 C c. ${ }^{25}$.

En el Considerando séptimo, el TS demuestra una falta de seguridad en sus propios planteamientos. Es la conclusión que cabe extraer de afirmaciones como ésta: «... aunque hubiere que estimar que el art. 1903 del C.Civ. había sido indebidamente aplicado al caso concreto - por no darse en él ninguna de las relaciones jurídicas que dicho precepto contempla, ni tampoco la vinculación de dependencia que en él se exige-...». En definitiva, el TS resta importancia a la posible aplicación del art. 1.903 C.c., al entender que el art. 1.902 C.c. podía ser aplicado a la propietaria del vehículo «que no se cuidó de elegir una persona que tuviera la necesaria prudencia para conducir un vehículo sin originar daños».

\section{B) Sentencias posteriores}

El razonamiento seguido por la STS (Sala 1a) 23 de febrero de 1976 tuvo, a pesar de sus defectos, una buena acogida en las sentencias de las Audiencias ${ }^{26}$. Por el contrario, el recurso al carácter abierto del art. 1.903 C.c. no ha vuelto a aparecer en las sentencias del TS.

En la STS (Sala 1') 23 de septiembre de $1988^{27}$, los daños fueron causados por

las previstas en los casos enumerados en este artículo. La Asamblea Plenaria no da lugar al recurso y aprueba la condena hecha sobre la base del párrafo primero del art. 1.384 C.c., abriéndose, por tanto, la puerta a la posibilidad de que existan supuestos de responsabilidad por hecho de otro diferentes a los recogidos expresamente en la norma. La información del caso se encuentra en G. VINEY, «Vers un élargissement de la catégorie des «persones dont on doit répondre»: la porte entrouverte sur une nouvelle interprétation de l'article 1384, alinéa ler, du Code civil», Dalloz, 1991, Chronique, pp. 157 y ss.

24 Al respecto, vid. R. DE ÁNGEL YAGÜEZ, «De nuevo sobre el problema de la aplicabilidad del artículo 1.903 del Código civil a las relaciones entre comitente y contratista (A propósito de las sentencias del Tribunal Supremo de 18 de junio y de 5 de julio de 1979)», Estudios de Deusto, Fasc. 65, 1980, p. 264.

25 Como señala E. QUIÑONERO CERVANTES, «Comentario a la Sentencia del Tribunal Supremo de 23 de febrero de 1976 sobre culpa extracontractual derivada de accidente de circulación. Aplicación analógica del artículo 1.903 del Código civil», Anales de Derecho (Universidad de Murcia), 1978.2, pp. 74 y 75, de la relación comodante-comodatario que existía entre la propietaria y el conductor del vehículo no cabe deducir responsabilidad contra la comodante. A su juicio, en el comodato el vehículo queda bajo la completa dirección del comodatario al que se transfiere.

26 SAT Madrid 24 de octubre de 1977 (RGD 1978, p. 23), SAT Zaragoza 11 de octubre de 1979 (RGD 1980, pp. 1.254 y ss.) y SAP Granada 18 de septiembre de 1989 (AC, Audiencias, 1990, $\mathrm{n}^{\circ} 1$ ), SAP Huesca 11 de enero de 1994 (AC, Audiencias, 1994, $\mathrm{n}^{\circ}$ 597) y SAP Albacete 11 de marzo de 1994 (AC, Audiencias, 1994, $\mathrm{n}^{\circ}$ 1.044). Otras declaran la aplicación del art. 1.903 C.c., sin recurrir al argumento analógico: SAP Palencia de 5 de abril de 1994 (AC, Audiencias, $n^{\circ} 751$ ) y SAP Sevilla (AC, Audiencias, $\mathrm{n}^{\circ} 1.291$ ).

27 RAJ n 6.854 
un automóvil que, con autorización, conducía el hijo (mayor de edad) de los propietarios. El recurrente en casación expuso la falta de dependencia, así como la no existencia de establecimiento o empresa (que permitiese aplicar el art. 1.903.IV C.c.).

Frente a estos argumentos, el TS contesta de forma poco clara ${ }^{28}$, calificando, además, erróneamente como «relación de carácter cuasi-negocial» lo que es un claro supuesto de comodato. Se descarta la aplicación del art. 1.903.IVC.c. (dice el TS que no aparecía acreditado que el fallecido hijo del recurrente actuara bajo dependencia laboral o empresarial de su padre titular del vehículo), pero la condena se mantiene, sin citar en ningún momento la norma aplicable al caso, porque «no puede rechazarse de modo general la idea de que la autorización concedida por el padre o la madre propietarios de un vehículo de motor para conducirlo de modo habitual, constituye un acto que si bien, en principio, de mero hecho, puede originar consecuencias jurídicas de las que aquéllos hayan de responder civilmente».

Sobre la cuestión que tratamos se ha pronunciado también la STS (Sala $\left.1^{\text {aa }}\right) 30$ de diciembre de $1992^{29}$. La autorización concedida al hijo para conducir no tenía por objeto, en este caso, un vehículo propiedad del padre, sino propiedad de la empresa a la que prestaba servicios el padre, que lo tenía a su disposición para el desempeño de su trabajo como cobrador. Consta como hecho probado que la empresa no permitió la utilización del vehículo por los familiares del cobrador. Tanto el Juzgado como la Audiencia condenaron solidariamente al conductor, al empleado (padre del conductor) y a la empresa propietaria del coche. La Audiencia basó la condena del empresario en el previsible asentimiento tácito de los órganos de la sociedad a la utilización del vehículo por familiares, dado que se le permitía al cobrador llevarse el automóvil a su domicilio y destinarlo a fines particulares. El TS, en cambio, estima el recurso de casación y absuelve a la empresa, por considerar que no hay relación de dependencia con el hijo del empleado, al que no se autorizó expresamente.

La lectura del fallo nos presenta como posible sujeto responsable ex art. 1.903.IV C.c. tanto al empleado como a la empresa.

En el primer caso, y aunque nada se diga en la sentencia (el único recurrente fue el empresario), parece que fue el art. 1.903.IV C.c. la norma aplicada para condenar al empleado por haber autorizado a su hijo la conducción del vehículo, siguiéndose, por tanto, una interpretación muy criticable y poco rigurosa con una recta aplicación de los presupuestos sobre los que se asienta esta responsabilidad,

28 Con razón, señala F. REGLERO CAMPOS, «Comentario a la STS (Sala $1^{\text {a }}$ ) 23 de septiembre de $1988 », C C J C, \mathrm{n}^{\circ} 18$, p. 860 , que lo verdaderamente criticable de la sentencia no es el fallo en sí, sino el hecho de haber utilizado una argumentación excesivamente confusa para sustentarlo.

29 RAJ n 10.565. 
al faltar la relación de dependencia, que no puede ser sustituida por una simple autorización de uso del vehículo.

En el segundo, la decisión del TS, como hemos visto, no hizo responsable a la empresa del daño causado por el hijo de su empleado, al no existir ni dependencia ni consentimiento expreso para usar el vehículo. Este planteamiento es correcto, pero no debió descartarse la responsabilidad de la empresa por la conducta de su empleado (cobrador que utilizaba habitualmente el vehículo). Al autorizar el uso privado del vehículo por su empleado, el empresario había extendido su área de responsabilidad, en la que bien pudieran entrar los daños que derivasen de la autorización que el empleado hiciese a sus familiares o a otras personas. No es tanto un problema de dependencia (la autorización del vehículo para fines privados se yuxtapone a la relación laboral) como de saber si la actuación del empleado entraba dentro de lo que puede considerarse ejercicio o desempeño de sus funciones, que es otro de los presupuestos de aplicación del precepto.

\section{EL ART. 120.6 DEL PROYECTO DE CÓDIGO PENAL DE 1994}

El análisis de la jurisprudencia permite, a nuestro juicio, extraer algunas conclusiones que ayudan a situar, en sus justos términos, la problemática que hoy existe en torno al préstamo de vehículos.

En primer lugar, el criterio de protección de la persona y de sus bienes jurídicos que inspira el Derecho de daños exige, sin lugar a dudas, que el titular del vehículo deba responder de los daños causados por las personas a las que autorizó para usarlo.

En segundo lugar, se debe señalar que la solución que ofrecen los arts. 22 C.p. y 1.903.IV C.c. no es la más adecuada. El inconveniente básico es la falta de dependencia que existe entre quien cede el vehículo y quien causa directamente el daño. Es cierto que ambas normas son objeto de una interpretación amplia en la jurisprudencia (así, por ejemplo, no se exige que concurra en el sujeto responsable la condición de empresario mercantil o laboral), pero existen ciertos límites, como la relación de dependencia, que, de traspasarse, hacen prácticamente irreconocible esta responsabilidad.

Las consideraciones anteriores son motivo más que suficiente para que se introduzca, en nuestras leyes, una norma que expresamente aborde la cuestión de la responsabilidad que deriva de los daños causados en el préstamo amistoso de vehículos.

La configuración del supuesto de hecho de la norma jurídica debería, sin embargo, realizarse en forma que permitiese incluir en él otras situaciones distintas de la cesión gratuita del automóvil, pero que participan de la misma problemática: el alquiler de vehículos, por ejemplo.

Además, sería conveniente plantear la responsabilidad de quien tiene poder de 
disposición sobre el vehículo no sólo en casos de conducciones autorizadas (que son las que se dan en el arrendamiento y comodato), sino también cuando el uso del vehículo por otra persona ha sido facilitado por su negligente conducta. Es cierto que no existe aquí autorización expresa o tácita, pero no debe excluirse que estas conducciones no autorizadas puedan engendrar responsabilidad en el propietario del vehículo ${ }^{30}$.

Por último, sería muy útil tomar en consideración los daños causados por vehículos de la empresa que son conducidos por empleados o trabajadores. La aplicación de los arts. 22.I C.p. y 1.903.IV C.c. presenta también algunos obstáculos, no por la dependencia (que claramente existe aquí), sino por la necesidad de que exista una conexión entre el daño causado por el dependiente y las funciones que le fueron asignadas. Junto a la dependencia, existe otro presupuesto de aplicación, que exige la producción de los daños «en el servicio de los ramos en que los tuvieran empleados, o con ocasión de sus funciones» (art. 1.903.IV C.c.) o «en el desempeño de sus obligaciones o servicio» (art. 22.I C.p.). En la mayoría de los casos, la conducción por el empleado del vehículo obedece a la realización de los fines propios de su cometido laboral, pero hay otros en los que el trabajador utiliza el vehículo de la empresa para fines particulares (visita de familiares, salir

30 Interesante es, a este respecto, la SAP Valencia 23 de noviembre de 1993 (AC, Audiencias, $1994, \mathrm{n}^{\circ} 398$ ), donde el propietario de un automóvil resulta responsable ex art. 1.903 C.c. por una conducción no autorizada de su hijo menor de edad.

El menor, Manuel T.S., cogió a su padre, Manuel T.G., las llaves del coche y sin su autorización, con la ayuda de unos amigos, sacó el turismo de la cochera en que se encontraba, empujándolo a fin de evitar que su padre pudiera oír el ruido del motor, y cuando lo había llevado tres calles más allá de su casa, subieron al mismo y se fueron. El vehículo era conducido por el hijo del propietario, produciéndose el accidente al salirse de la calzada, del que resultó lesionado el menor Rafael O.A., que tardó en curar sesenta días y tuvo como secuela la pérdida del bazo y parálisis permanente del nervio facial izquierdo.

La demanda fue interpuesta por el padre del menor lesionado contra Manuel T.S., Manuel T.G. y la entidad aseguradora. El Juzgado condenó a los demandados a la suma de seis millones ciento ochenta mil pesetas, debiendo responder la entidad asegura sólo con cargo al seguro obligatorio.

Contra dicha resolución apeló la aseguradora, por entender que el suceso estaba excluido de cobertura, incluso con cargo al seguro obligatorio, al haber sido hurtado o robado el vehículo. Para la Audiencia, el propio lesionado, Rafael O.A., contribuyó con su esfuerzo a sacar el vehículo del garaje y voluntariamente subió al mismo sabiendo que su uso lo era sin conocimiento ni autorización del propietario, concurriendo la causa de exclusión que alega la entidad aseguradora en base a los arts. 3.3 del RDL 1.301/1986, de 28 de junio y 12.1, c) RD 2.641/1986, de 30 de diciembre. Se revoca la sentencia impugnada, sin imponer condena alguna a la aseguradora.

Respecto de Manuel T.G. y Manuel T.S., queda firme la condena, al no recurrir tal pronunciamiento, examinando únicamente la sentencia de la Audiencia el alcance cuantitativo que haya de darse a la indemnización, que sí fue objeto de impugnación en la adhesión implícita al recurso que contiene el escrito de impugnación parcial presentado por los citados demandados. Se afirma que los demandados incurrieron en responsabilidad civil por la vía de los arts. 1.902 y 1.903 C.c., aun cuando el lesionado también incurrió en culpa al ocupar una plaza en vehículo conducido por Manuel T.S., conociendo que carecía del correspondiente permiso de conducir. La sentencia hace uso del instituto de la compensación de culpas, reduciendo en un $90 \%$ las indemnizaciones inicialmente concedidas por el Juzgado de Primera Instancia. 
de copas con los amigos, etc.). Cabe preguntarse, con respecto a estos últimos, si la conexión entre el daño y las funciones sigue dándose. La jurisprudencia entiende que el empresario no responde en los casos de uso particular del vehículo por el empleado ${ }^{31}$. A nuestro juicio, debería, sin embargo, responder el empresario en estas situaciones, ya que no puede desentenderse del posible mal uso que haga su empleado del vehículo puesto a su disposición, y la mejor solución al respecto sería la que diese una norma que expresamente recogiese este supuesto, no siendo ya necesario el recurso a los arts. 22.I C.p. y 1.903.IV C.c.

El Proyecto de Código penal establece, en su art. $120.6^{\circ}$, la responsabilidad civil subsidiaria de «las personas naturales o jurídicas titulares de vehículos susceptibles de crear riesgos para terceros, por los delitos o faltas cometidos en la utilización de los mismos por sus dependientes o representantes o personas autorizadas».

La inclusión de esta norma es muy acertada, y viene a confirmar que el art. 22.I C.p. (cuyo equivalente en el Proyecto es el art. $120.4^{\circ}$ ) no es una solución adecuada para los problemas de responsabilidad civil que derivan del uso de automóviles por personas autorizadas. En la nueva norma, se incluyen tanto los supuestos de cesión gratuita como de alquiler de vehículo y se recoge la conducción de vehículos por dependientes, todo lo cual evitará el recurso al art. 120.4 .

Sin embargo, a nuestro juicio la norma podría ser un poco más precisa y tratar de dar solución a algunos problemas que pueden plantearse en la práctica.

En este sentido, podría también declararse la responsabilidad civil subsidiaria del titular del vehículo por los delitos o faltas cometidos por personas no autorizadas, pero cuyo acceso al vehículo ha sido facilitado por una conducta descuidada o negligente del titular. No parece que la actual redacción del art. $120.6^{\circ}$ permita declarar esta responsabilidad.

Con relación a la responsabilidad del titular del vehículo por sus dependientes, hemos dicho que nos parece acertada su expresa mención por el Proyecto de Código penal. Ahora bien, esta responsabilidad debe cubrir tanto las conducciones autorizadas como aquellas que no lo son y que, por tanto, forman parte de un uso particular del vehículo de la empresa por el empleado. La responsabilidad empresarial debe también poder ser exigida en este segundo caso, dado que han sido las funciones o cometidos laborales las que han facilitado al empleado el acceso al vehículo. Al referirse, sin más, a la responsabilidad del titular del vehículo por los delitos o faltas cometidos por los dependientes, ¿se entiende incluido, en el Proyecto, el caso del uso particular del vehículo de la empresa por el dependiente?

31 SSTS (Sala $2^{\mathrm{a}}$ ) 13 de mayo de 1935 (RAJ n ${ }^{\circ}$ 964), 22 de abril de 1955 (RAJ n ${ }^{\circ} 1.245$ ), 9 de diciembre de 1960 (RAJ n $\left.^{\circ} 4.117\right), 9$ de marzo de 1964 (RAJ ${ }^{\circ} 1.491$ ), 21 de septiembre de 1965 $\left(\mathrm{RAJ} \mathrm{n}^{\circ} 3.792\right.$ ) y 20 de abril de $1972\left(\mathrm{RAJ} \mathrm{n}^{\circ} 1.745\right.$ ); SSTS (Sala $\left.1^{\mathrm{a}}\right) 6$ de julio de $1934\left(\mathrm{JC}^{\circ}\right.$ 96) y 22 de octubre de 1965 (RAJ n $\left.{ }^{\circ} 4.603\right)$. 
Las observaciones hechas apuntan hacia la conveniencia de que el Proyecto de Código penal distinga entre conducciones autorizadas y no autorizadas, ya que en estas últimas puede también venir, en ciertos casos, justificada la imposición de responsabilidad en el titular del vehículo. En cualquier caso, aunque el art. $120.6^{\circ}$ conserve su actual redacción, no ofrece duda que la situación legal (al menos, en lo que se refiere a la responsabilidad civil subsidiaria, pues la modificación no afecta a los arts. 1.902 y ss. C.c.) habrá mejorado considerablemente.

Puede ser útil, a este respecto, tomar en consideración la forma en que se regulan estas situaciones en otros ordenamientos, como el alemán. Mientras el BGB basa el sistema de responsabilidad civil en la culpa, las leyes especiales se han ocupado de regular la responsabilidad por riesgo (Gefahrdungshaftung), uno de cuyos supuestos más importantes es la responsabilidad del tenedor del automóvil (die Haftung des Kraftfahrzeughalters). Esta responsabilidad se encuentra recogida en los $\S \S 7$ y siguientes de la Strassenverkehrsgesetz (StVG) de 19 de diciembre de 1952 .

Conforme a la ley, aparece como responsable, en primer término, el tenedor (Halter) del vehículo, que la jurisprudencia define como «quien por su propia cuenta lo tiene en uso y posee el poder de disposición, que ese uso presupone» ${ }^{32}$. En la mayoría de los casos, se trata del propietario ${ }^{33}$; en una cesión larga, podía serlo el cesionario, que asume los gastos de mantenimiento del vehículo ${ }^{34}$; en el alquiler de vehículo de corta duración, el arrendador es el único que es considerado Halter $^{35}$.

Excepcionalmente, esta responsabilidad por riesgo puede alcanzar, según previene el $\S 7 . I I I$ StVG, a quien utiliza el vehículo sin el conocimiento y la voluntad del Halter: es el llamado conductor no autorizado (Schwarzfahrer ${ }^{36}$ que, en principio, está llamado a responder en lugar del tenedor.

Sin embargo, ocurre que, junto al conductor no autorizado, puede seguir estando obligado el tenedor, de acuerdo con lo dispuesto en el mismo § 7.III StVG, cuando la utilización del vehículo fue posible por su culpa, como sería el caso de una descuidada conservación de las llaves o de no cerrar el vehículo tras haberlo aparcado ${ }^{37}$.

32 BGH 29 de mayo de 1954 (BGHZ 13, 351, 354).

33 Vid. D. MEDICUS, Schuldrecht II, Besonderer Teil, München, 1992, p. 396.

34 Así, K. LARENZ, Lehrbuch des Schuldrechts, Band II, Besonderer Teil, München, 1981, p. 712.

Aquí sí tiene sentido conocer la duración de la cesión, pues cuando la duración es larga ello indica que el cedente pierde control sobre el vehículo. Lo que no es lógico, como vimos en su momento, es plantear una distinción entre cesión permanente y ocasional, cuando se trata de aplicar una norma como la del art. 22.I C.p., que indefectiblemente exige una relación de dependencia.

35 BGH 23 de mayo de 1960 (BGHZ 32, 331).

36 Al respecto, vid. E. VON HIPPEL, «Zur Haftung bei Schwarzfahrten», VersR, 1966, p. 507, nota 1 .

37 Sobre estos casos, vid. D. MEDICUS, op. cit., p. 396. 
La última previsión del § 7.III StVG contiene una excepción a la regla que disponía la responsabilidad del conductor no autorizado en lugar de la del tenedor del vehículo. Se considera que la regla no tiene aplicación cuando los viajes sin conocimiento y voluntad del Halter han sido realizados por su chófer o por las personas a las que cedió el uso del vehículo ${ }^{38}$, entendiendo, en ambos casos, que la única responsabilidad es la que recae sobre el tenedor ${ }^{39}$.

38 En el primer caso (Anstellung für den Betrieb des Kraftfahrzeugs), encontramos a una persona que ha sido encargada para conducir el vehículo o para disponer su uso. El término angestellt comprende cualquier encargo remunerado, sin tomar en consideración el carácter jurídico-laboral. Y en el segundo (Überlassung des Kraftfahrzeugs), el tenedor ha concedido a otra persona la posibilidad material de utilizar el vehículo, sin que por ello esta otra persona se convierta en tenedor: son, sobre todo, casos de préstamo y de arrendamiento. Vid., sobre ello, R. GREGER, Zivilrechtliche Haftung im Straßenverkehr, Berlin, New York, 1990, pp. 108 y 109.

39 Sobre el particular, vid. W. GELHAAR/H. THULEWEIT, Das Haftpflichtrecht des Straßenverkehrs, Tübingen, 1969, p. 31. 